\title{
Inhibition of matrix metalloproteinases expression in human dental pulp cells by all-trans retinoic acid
}

\author{
Jin Man Kim ${ }^{1}$, Sang Wook Kang ${ }^{2}$, Su-Mi Shin ${ }^{1}$, Duck Su Kim ${ }^{1}$, Kyong-Kyu Choi ${ }^{1}$, Eun-Cheol Kim ${ }^{2}$ \\ and Sun-Young Kim ${ }^{1}$
}

\begin{abstract}
All-trans retinoic acid (ATRA) inhibits matrix metalloproteinase (MMP)-2 and MMP-9 in synovial fibroblasts, skin fibroblasts, bronchoalveolar lavage cells and cancer cells, but activates MMP-9 in neuroblast and leukemia cells. Very little is known regarding whether ATRA can activate or inhibit MMPs in human dental pulp cells (HDPCs). The purpose of this study was to determine the effects of ATRA on the production and secretion of MMP-2 and -9 in HDPCs. The productions and messenger RNA (mRNA) expressions of MMP-2 and -9 were accessed by gelatin zymography and real-time polymerase chain reaction (PCR), respectively. ATRA was found to decrease MMP-2 level in a dose-dependent manner. Significant reduction in MMP-2 mRNA expression was also observed in HDPCs treated with $25 \mu \mathrm{mol} \cdot \mathrm{L}^{-1}$ ATRA. However, HDPCs treated with ATRA had no effect on the pattern of MMP-9 produced or secreted in either cell extracts or conditioned medium fractions. Taken together, ATRA had an inhibitory effect on MMP-2 expression in HDPCs, which suggests that ATRA could be a candidate as a medicament which could control the inflammation of pulp tissue in vital pulp therapy and regenerative endodontics.
\end{abstract}

International Journal of Oral Science (2013) 6, 150-153; doi:10.1038/ijos.2013.63; published 6 September 2013

Keywords: all-trans retinoic acid; human dental pulp cell; matrix metalloproteinase; zymography

\section{INTRODUCTION}

Matrix metalloproteinases (MMPs) are a family of structurally related zinc-dependent proteases that are classified into several subgroups: collagenases (MMP-1, -8, -13 and -18), gelatinases (MMP-2 and -9), matrilysins (MMP-7 and -26), transmembrane MMPs (MMP-14, -15, $-16,-17,-24$ and -25$)$, stromelysins (MMP-3, -10 and -11 ) and others. ${ }^{1-2}$ Two gelatinases, MMP-2 and -9 , are capable of degrading denatured interstitial collagens (gelatins), lamins, elastins, fibronectins and basement membrane zone-associated collagens. ${ }^{3}$ They are involved in normal turnover of extracellular matrix, tumor invasion and chronic inflammatory disease. MMP-2 and -9 were found to be upregulated in inflamed pulp tissues and periapical lesions in vivo. ${ }^{4}$ Furthermore, MMP-2 and -9 are regulated by cytokines and lipopolysaccharide in human dental pulpal cells (HDPCs) and are thought to play crucial roles in pulpal inflammation. ${ }^{4-6}$

It is desirable to develop a medicament for use in direct pulp capping treatment that inhibits early pulpal inflammation. The agents that inhibit MMP expression could be candidates for this type of treatment, to prevent and/or treat pulpal inflammation by mechanical, chemical and microbial irritants. Previous studies have demonstrated that peroxisome proliferator activated receptor gamma, zinc oxide, TGF- $\beta$, protein synthesis inhibitor (cycloheximide), protein kinase $\mathrm{C}$ inhibitor, tyrosine kinase inhibitor (Herbimycin A) and dexamethasone all inhibit MMP expression in HDPCs. ${ }^{5,7-9}$
Retinoids are derivatives of vitamin A and are involved in a number of biological processes. ${ }^{10}$ Retinoids have been found to inhibit inflammation, thrombosis, platelet adhesion and stimulate fibrinolysis. ${ }^{11}$ Especially, all-trans retinoic acid (ATRA) was found to be a very potent metabolite of retinol, exerting pleiotropic effects on many different biological processes. Previous in vitro studies using synovial fibroblasts, skin fibroblasts, bronchoalveolar lavage cells and cancer cells showed that ATRA inhibits MMP-2 and -9 expression. ${ }^{12-15}$ In contrast, ATRA can induce MMP-9 expression and activity in neuroblastic cell lines, myleoid leukaemia cells and dendritic cells. ${ }^{16-18}$ Thus, it remains uncertain whether ATRA incites MMPs inductive or inhibitory effects in HDPCs.

The aim of this study was to investigate the effects of ATRA on MMP-2 and MMP-9 production and messenger RNA (mRNA) expression using gelatin zymography and real-time polymerase chain reaction (PCR) in HDPCs.

\section{MATERIALS AND METHODS}

Primary culture of HDPCs

HDPCs were obtained from healthy premolars, which were extracted with informed consent from patients who presented for orthodontic treatment. The protocol of this study was approved by Institutional Review Board in Kyung Hee University Dental Hospital (KHD IRB1106-02). Pulp tissue was collected from the coronal part after resection of each tooth at the cementoenamel junction. Pulp tissue was washed in

${ }^{1}$ Department of Conservative Dentistry, School of Dentistry, Kyung Hee University, Seoul, Korea and ${ }^{2}$ Department of Maxillofacial Tissue Regeneration, School of Dentistry, Kyung Hee University, Seoul, Korea

Correspondence: Dr SY Kim, Department of Conservative Dentistry, School of Dentistry, Kyung Hee University, 1 Hoegi-dong, Dongdaemun-gu, Seoul 130-701, Korea

E-mail: kimsunyoung@khu.ac.kr

Accepted 26 June 2013 
phosphate-buffered saline (Gibco, Invitrogen, Karlsruhe, Germany) for $1 \mathrm{~min}$, cut into small pieces, transferred to cell-culture plates and incubated with Dulbecco's modified Eagle's medium containing 10\% fetal bovine serum (Gibco BRL, Life Technologies, Grand Island, NY, USA), penicillin-G $(100 \mathrm{U} \cdot \mathrm{mL})$, streptomycin $(100 \mu \mathrm{g} \cdot \mathrm{mL})$ and Fungizone $(0.25 \mathrm{~g} \cdot \mathrm{mL})$ (GeminiBio-Products Inc., Woodland, CA, USA) at $37{ }^{\circ} \mathrm{C}$ in a humidified atmosphere of $5 \% \mathrm{CO}_{2}$. Migration of cells from the pulpal tissue occurred 1 week later, and cultures were established and maintained in standard culture medium. Medium was refreshed three times per week, and cells were split, after reaching confluence. Pulp cells between the third and eighth passages were used in this study.

\section{Cytotoxicity}

Cell viability was determined using 3-(4,5-dimethylthiazol-2-yl)-2,5diphenyltetrazolium bromide (MTT) assay kit (Boehringer Mannheim, Mannheim, Germany) as per the manufacturer's protocol; ${ }^{19} 1 \times 10^{4}$ cells were seeded in each well of 96-well plate with $200 \mu \mathrm{L}$ culture media. A $10 \mu \mathrm{L}$ sample of MTT labelling reagent was added to each well and the plates were incubated for $4 \mathrm{~h}$. The cells were then incubated in $100 \mu \mathrm{L}$ of the solubilisation solution for $12 \mathrm{~h}$. The absorbance was measured with a microtiter plate reader (Bio-Tek, Winooski, VT, USA) at a test wavelength of $595 \mathrm{~nm}$ with a reference wavelength of $690 \mathrm{~nm}$. Cell viability was calculated as a percentage relative to the reference. A toxic concentration that allowed $50 \%$ of the cells to survive $\left(\mathrm{TC}_{50}\right)$ was determined using a dose-response curve according to the concentration of ATRA.

\section{Gelatin zymography}

Cultured HDPCs were treated with ATRA solution of 1, 10, 25 and $50 \mu \mathrm{mol} \cdot \mathrm{L}^{-1}$. After $24 \mathrm{~h}$, supernatant from the treated cells was collected and mixed at a $1: 1$ ratio with non-reducing sample buffer $(2 \%$ sodium dodecyl sulphate, $125 \mathrm{mmol} \cdot \mathrm{L}^{-1}$ Tris- $\mathrm{HCl}(\mathrm{pH} 6.8), 10 \%$ glycerol, $0.001 \%$ bromophenol blue) for preparing samples. The samples were electrophoresed on $10 \%$ polyacrylamide gels copolymerized with $0.3 \%$ gelatin. After isolating the proteins, the gel was rinsed twice with $2 \%$ Triton $\mathrm{X}-100$ for $20 \mathrm{~min}$ at room temperature and then incubated in $50 \mathrm{mmol} \cdot \mathrm{L}^{-1}$ Tris- $\mathrm{HCl}(\mathrm{pH} 7.9), 5 \mathrm{mmol} \cdot \mathrm{L}^{-1} \mathrm{CaCl}_{2}$ and $1 \mathrm{mmol} \cdot \mathrm{L}^{-1} \mathrm{ZnCl}_{2}$ overnight at $37{ }^{\circ} \mathrm{C}$. The gel was stained with $0.25 \%$ Coomassie brilliant blue solution and then de-stained with $5 \%$ methanol and $8 \%$ acetic acid. The gel was converted into digital images and the band density was measured through Image-Pro Plus 4.5 software (Media Cybernetics, Silver Spring, MD, USA).

\section{RNA isolation and real-time PCR}

RNA was extracted from the treated cells using RNAiso Plus (TaKaRa Bio, Shiga, Japan). cDNA was synthesized from $400 \mathrm{ng}$ of total RNA using the PrimeScript RT reagent kit (TaKaRa Bio, Otsu, Japan) according to the manufacturer's instructions. One-tenth of the cDNA obtained was added for a final volume of $20 \mu \mathrm{L}$ for each reaction containing SYBR Green I (TaKaRa Bio, Shiga, Japan). The primers for MMP-2, -9 and glyceraldehyde 3-phosphate dehydrogenase were as follows (sense/antisense):

MMP-2: 5'-ATC CTG GCT TTC CCA AGC TC-3'/3'-CAC CCT TGA AGA AGT AGC TGT G-5'.

MMP-9: 5'-GGG CTT AGA TCA TTC CTC AGT G-3'/3'-GCC ATT CAC GTC GTC CTT AT-5'.

Glyceraldehyde 3-phosphate dehydrogenase: 5'-GGT GAA GGT CGG AGT CAA CG-3'/3'-CCA GTA GGT ACT GTT GAA-5'.
Reactions were run on an ABI Step One real-time PCR system (Applied Biosystems, Foster City, CA, USA) with the following program: 45 cycles of $95{ }^{\circ} \mathrm{C}$ for $10 \mathrm{~s}, 60{ }^{\circ} \mathrm{C}$ for $15 \mathrm{~s}$ and $72{ }^{\circ} \mathrm{C}$ for $20 \mathrm{~s}$. For relative comparisons of each gene, we analysed the threshold cycle $\left(C_{\mathrm{t}}\right)$ value of the real-time PCR data using the $2^{-\Delta \Delta C_{t}}$ method. ${ }^{20}$

\section{Statistical analysis}

All experimental procedures for this study were performed in triplicate. One-way analysis of variance and Tukey's multiple comparison test were used to analyse the results of the gelatin zymography. Student's $t$-test was used to determine differences in gene expression between the control group and the ATRA group. A $P$ value of $<0.05$ was considered statistically significant.

\section{RESULTS}

\section{Effect of ATRA on cell viability}

To examine the cytotoxic potential of ATRA, its effect on the viability of HDPCs was initially measured by MTT assay (Figure 1). Although ATRA had no cytotoxic effect when tested at the $1-50 \mu \mathrm{mol} \cdot \mathrm{L}^{-1}$ concentrations, we found that ATRA exhibited cytotoxicity in HDPCs at higher concentrations $\left(>75 \mu \mathrm{mol} \cdot \mathrm{L}^{-1}\right)$. The $\mathrm{TC}_{50}$ of ATRA was about $70 \mu \mathrm{mol} \cdot \mathrm{L}^{-1}$ according to the dose-response curve.

\section{Effect of ATRA on MMP-2 and MMP-9 production}

The protein levels of MMP-2 and -9 were determined using gelatin zymography in conditioned media from HDPC cultures. As shown in Figure $2 \mathrm{a}$, zymography revealed that the main gelatinases secreted by HDPCs migrated at $72 \mathrm{kDa}$, which represents the MMP-2 pro-form, and at $62 \mathrm{kDa}$, which represents the MMP-2 active-form. Minor gelatinolytic bands were rarely observed in the $92 \mathrm{kDa}$ region, which represents the MMP-9 pro-form. The level of MMP-2 was inhibited by ATRA in a dose-dependent manner. The active form of MMP-2 was suppressed at $10 \mu \mathrm{mol} \cdot \mathrm{L}^{-1}$, and both pro- and active-form MMP-2 were clearly suppressed at $25 \mu \mathrm{mol} \cdot \mathrm{L}^{-1}$. Figure $2 \mathrm{~b}$ shows the relative MMP-2 activity containing both pro- and active-forms according to ATRA concentration.

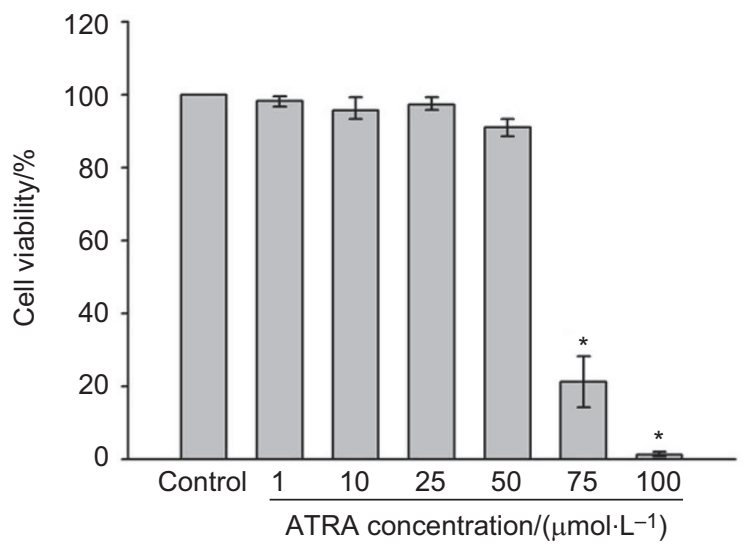

Figure 1 Effects of ATRA on the cytotoxicity of HDPCs. Cells were treated with the indicated concentrations of ATRA for $24 \mathrm{~h}$. Cell viability was measured using MTT assay. Data are representative of three independent experiments. *Statistically significant differences compared with the control $(P<0.05)$. ATRA, all-trans retinoic acid; HDPC, human dental pulp cell; MTT, 3-(4,5dimethylthiazol-2-yl)-2,5-diphenyltetrazolium bromide. 

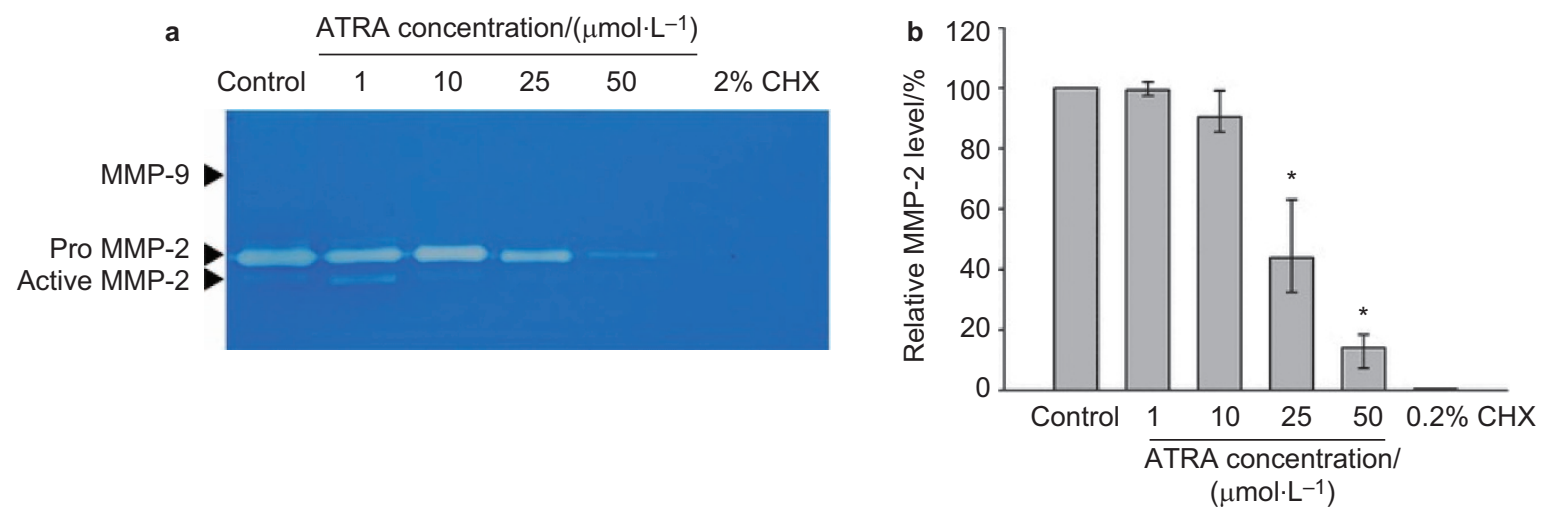

Figure 2 Effects of ATRA on MMP-2 and MMP-9 expression. Cells were incubated with the indicated concentrations of ATRA for $24 \mathrm{~h}$. (a) MMPs expression was determined by zymogram. (b) Densitometric analysis of total expression of MMP-2. Relative MMP-2 level is comparod to negative control. The negative control group contains only serum-free DMEM with $1 \%$ DMSO and the positive control group contains $0.2 \% \mathrm{CHX}$ solution. These data are representative of three independent experiments. *Statistically significant difference from the negative control group $(P<0.05)$. ATRA, all-trans retinoic acid; CHX, cycloheximide; DMEM, Dulbecco's modified Eagle's medium; DMSO, dimethyl sulphoxide; MMP, matrix metalloproteinase.
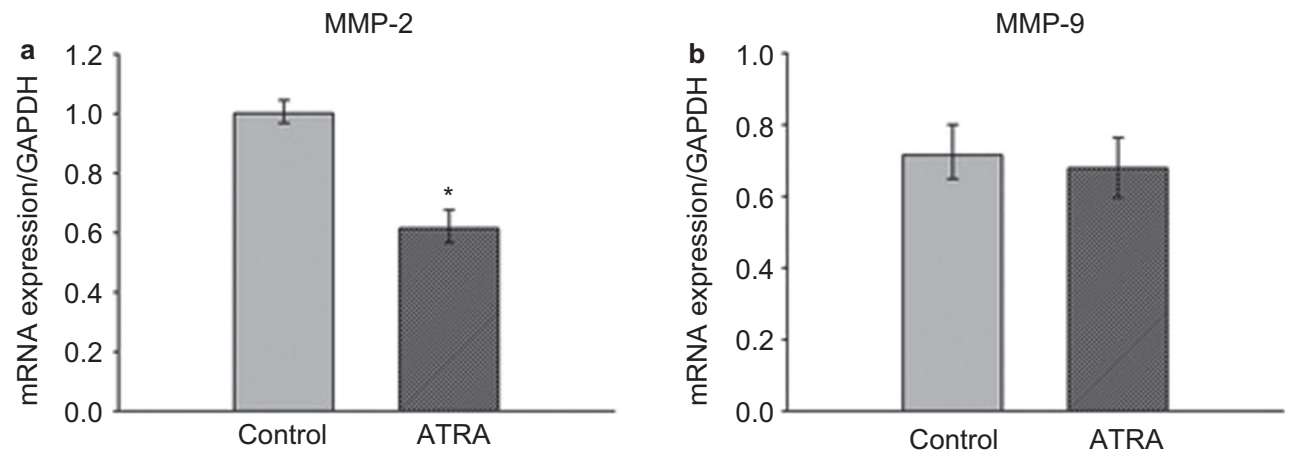

Figure 3 Effects of ATRA on mRNA expression in MMP-2 and MMP-9. (a) MMP-2; (b) MMP-9. Cells were incubated with $25 \mu \mathrm{mol} \cdot \mathrm{L}^{-1}$ ATRA for $24 \mathrm{~h}$. mRNA were assessed using real-time PCR. Similar data were obtained from three independent experiments. *Statistically significant difference from the control $(P<0.05)$. ATRA, all-trans retinoic acid; MMP, matrix metalloproteinase; mRNA, messenger RNA; PCR, polymerase chain reaction.

\section{Effect of ATRA on MMP-2 and MMP-9 mRNA expression}

To assess whether ATRA affects MMP-2 and -9 by regulation at the transcriptional level, we studied mRNA expression for MMPs using real-time PCR. Figure 3 demonstrates a significant reduction in MMP2 mRNA expression after treating cells with $25 \mu \mathrm{mol} \cdot \mathrm{L}^{-1}$ ATRA for $24 \mathrm{~h}$, as compared to the control. However, MMP-9 expression was not found to be significantly altered after ATRA treatment.

\section{DISCUSSION}

To our knowledge, this is the first study to examine the effects of ATRA on activity and expression of MMP-2 and -9 in HDPCs. The mechanisms and regulation of MMPs in HDPCs are not fully understood. The MMP pathway is centrally involved in the dissolution of all unmineralized connective tissues and perhaps in the resorption of bone as well. ${ }^{3}$ MMP-2 and -9 are of particular interest because they are synthesized by HDPCs and have been implicated in the pathogenesis of pulpal inflammation. ${ }^{4-6}$ In the present study, the main gelatinolytic proteinase secreted by the pulp cells was MMP-2, and only minimal amounts of MMP-9 were detected. We showed that ATRA could suppress the MMP-2 expression significantly in HDPCs at concentrations that did not have cytotoxic effects.

ATRA is the most activated retinoid in the human body and medates various cellular functions by acting on transcription factors. ATRA is a lipophilic molecule with a low molecular weight $(300 \mathrm{Da})$ but partial hydrophilicity, so that it can efficiently diffuse through water-soluble phases as well as hydrophobic membranes. ${ }^{10}$ This feature makes ATRA an effective signal molecule, regulating gene expression by spreading rapidly in a specific receptor of cells, such as the retinoic acid receptor (RAR- $\alpha,-\beta,-\gamma)$ and retinoid X receptor (RXR- $\alpha,-\beta,-\gamma)$. Until recently, more than 500 genes were suggested to be regulatory targets of retinoids, ${ }^{10}$ including genes related to MMPs, such as stromelysin-1, collagenases and gelatinases. Specifically, these MMP-related genes are suppressed by the antagonizing action of retinoids. Additionally, retinoids are known to have negative gene regulatory activities on inflammatory proteins, including $\mathrm{JE} /$ monocyte chemoattractant protein-1, inducible nitric oxide synthase, tumor-necrosis factor- $\alpha$ and interleukin- $2{ }^{21}$ These regulatory functions of retinoids on gene expression could be a basis for use as therapeutic agents for inflammatory tissue destruction.

In the present study, we found that MMP-2 expression was suppressed at similar levels at both the protein level and mRNA level (Figures $2 \mathrm{~b}$ and 3 ). This suggests that ATRA could suppress MMP-2 expression in HDPCs through the intracellular regulation of gene expression. The reason why ATRA showed a suppressive effect on the MMP-2 but not on the MMP-9 is not obvious. The role of ATRA in regulating MMPs is not well understood, and previous studies have reported conflicting results. ATRA has been reported to 
reduce the production of gelatinases (MMP-2 and -9) in fibroblasts and cancer cells, ${ }^{12-15}$ but to enhance their expression in Sertoli cells, dendritic cells and liver tissue. ${ }^{18,22-23}$ These observations suggest that the effect of ATRA on MMP-2 and MMP-9 may be species-, tissue- or cell type-specific, and/or temporally- and spatially-specific. Another thing to consider is that in the present study, MMP-9 does not appear to be well expressed in healthy HDPCs. Not only was MMP-9 rarely detected in the gelatin zymography of the control group in the present study, but previous studies have also reported that MMP-9 was expressed in HDPCs only under specific conditions, such as chronic inflammation. ${ }^{5,24}$ In this regard, further research is needed to investigate ATRA's effects on MMP expression in the inflammatory condition of pulp cells through culturing cells from inflamed pulp or application of inflammatory cytokines to pulp cells.

In the present study, we tested an ATRA dose of $25 \mu \mathrm{mol} \cdot \mathrm{L}^{-1}$ in real-time PCR since the concentration showed no cytotoxic effects but significant inhibition of MMP-2 activity. The suppressive effect of ATRA on MMPs has been identified in similar concentrations in other kinds of cells. Dutta et al. ${ }^{25}$ reported that the treatment of $30 \mu \mathrm{mol} \cdot \mathrm{L}^{-1}$ ATRA induced the suppression of MMP-2 activity. Roomi et al. ${ }^{15}$ demonstrated that both MMP-2 and -9 were inhibited in malignant mesothelioma cell lines with $50 \mu \mathrm{mol} \cdot \mathrm{L}^{-1}$ ATRA treatment. Clark et $a .^{26}$ reported that the suppression of human skin fibroblast MMPs was at a maximum $24 \mathrm{~h}$ after treatment with $10 \mu \mathrm{mol} \cdot \mathrm{L}^{-1}$ ATRA. Although the types of cells that were treated with ATRA differed among these previous studies, the concentration of ATRA inducing MMP inhibition was similar in terms of the concentration range $\left(10-50 \mu \mathrm{mol} \cdot \mathrm{L}^{-1}\right)$ of the present study that induced MMP-2 suppression without a cytotoxic effect.

In summary, in the present study, we found that ATRA has a suppressive effect on MMP-2 expression in HDPCs. This suggests that ATRA, which is already being used as a therapeutic agent in many biomedical fields, could also be a candidate for use in regenerative endodontics and vital pulp therapy, such as direct pulp capping by suppressing tissue destruction and inflammatory reaction. Further research is needed to investigate the cellular mechanism underlying the inhibition of MMP expression and the possible complications for the clinical efficacy of ATRA.

\section{ACKNOWLEDGEMENTS}

This study was supported by Basic Science Research Program through the National Research Foundation of Korea funded by the Ministry of Education, Science and Technology (No. 2012R1A1A1001473).

1 Visse R, Nagase H. Matrix metalloproteinases and tissue inhibitors of metalloproteinases: structure, function, and biochemistry. Circ Res 2003; 92(8): 827-839.

2 Snoek-van Beurden PA, von den Hoff JW. Zymographic techniques for the analysis of matrix metalloproteinases and their inhibitors. Biotechniques 2005; 38(1): 73-83.

3 Chang YC, Lai CC, Yang SF et al. Stimulation of matrix metalloproteinases by blackpigmented Bacteroides in human pulp and periodontal ligament cell cultures. J Endod 2002; 28(2): 90-93.

4 Shin SJ, Lee JI, Baek SH et al. Tissue levels of matrix metalloproteinases in pulps and periapical lesions. J Endod 2002; 28(4): 313-315.
5 Chang YC, Yang SF, Hsieh YS. Regulation of matrix metalloproteinase-2 production by cytokines and pharmacological agents in human pulp cell cultures. J Endod 2001; 27(11): 679-682.

6 Tsai $\mathrm{CH}$, Chen YJ, Huang FM et al. The upregulation of matrix metalloproteinase-9 in inflamed human dental pulps. J Endod 2005; 31(12): 860-862.

7 Yu MK, Lee JC, Kim JH et al. Anti-inflammatory effect of peroxisome proliferator activated receptor gamma on human dental pulp cells. J Endod 2009; 35(4): 524-528.

8 Santos MC, de Souza AP, Gerlach RF et al. Inhibition of human pulpal gelatinases (MMP-2 and MMP-9) by zinc oxide cements. J Oral Rehabil 2004; 31(7): 660-664.

9 Huang FM, Yang SF, Hsieh YS et al. Examination of the signal transduction pathways involved in matrix metalloproteinases-2 in human pulp cells. Oral Surg Oral Med Oral Pathol Oral Radiol Endod 2004; 97(3): 398-403.

10 Blomhoff R, Blomhoff HK. Overview of retinoid metabolism and function. J Neurobiol 2006; 66(7): 606-630.

11 Thacher SM, Vasudevan J, Chandraratna RA. Therapeutic applications for ligands of retinoid receptors. Curr Pharm Des 2000; 6(1): 25-58.

12 Brinckerhoff CE, McMillan RM, Dayer JM et al. Inhibition by retinoic acid of collagenase production in rheumatoid synovial cells. N Engl J Med 1980; 303(8): 432-436.

13 Bauer EA, Seltzer JL, Eisen AZ. Inhibition of collagen degradative enzymes by retinoic acid in vitro. J Am Acad Dermatol 1982; 6(4 Pt 2 Suppl): 603-607.

14 Frankenberger M, Hauck RW, Frankenberger B et al. All trans-retinoic acid selectively down-regulates matrix metalloproteinase-9 (MMP-9) and up-regulates tissue inhibitor of metalloproteinase-1 (TIMP-1) in human bronchoalveolar lavage cells. Mol Med 2001; 7(4): 263-270.

15 Roomi MW, Monterrey JC, Kalinovsky T et al. Modulation of MMP-2 and MMP-9 by cytokines, mitogens and inhibitors in lung cancer and malignant mesothelioma cell lines. Oncol Rep 2009; 22(6): 1283-1291.

16 Chambaut-Guerin AM, Herigault S, Rouet-Benzineb P et al. Induction of matrix metalloproteinase MMP-9 (92-kDa gelatinase) by retinoic acid in human neuroblastoma SKNBE cells: relevance to neuronal differentiation. J Neurochem 2000; 74(2): 508-517.

17 Shibakura M, Niiya K, Kiguchi T et al. Simultaneous induction of matrix metalloproteinase- 9 and interleukin 8 by all-trans retinoic acid in human PL-21 and NB4 myeloid leukaemia cells. Br J Haematol 2002; 118(2): 419-425.

18 Darmanin S, Chen J, Zhao S et al. All-trans retinoic acid enhances murine dendritic cell migration to draining lymph nodes via the balance of matrix metalloproteinases and their inhibitors. J Immunol 2007; 179(7): 4616-4625.

19 Ferreira MB, Myiagi S, Nogales CG et al. Time- and concentration-dependent cytotoxicity of antibiotics used in endodontic therapy. J App/ Oral Sci 2010; 18(3): 259-263.

20 Livak KJ, Schmittgen TD. Analysis of relative gene expression data using real-time quantitative PCR and the 2(-Delta Delta C(T)) method. Methods 2001; 25(4): 402-408.

21 Nagpal S, Chandraratna RA. Vitamin A and regulation of gene expression. Curr Opin Clin Nutr Metab Care 1998; 1(4): 341-346.

22 Dalmolin RJ, Zanotto-Filho A, de Oliveira RB et al. Retinol and retinoic acid increase MMP-2 activity by different pathways in cultured Sertoli cells. Free Radic Res 2007; 41(12): 1338-1347.

23 Wang $\mathrm{H}$, Dan Z, Jiang $\mathrm{H}$. Effect of all-trans retinoic acid on liver fibrosis induced by common bile duct ligation in rats. J Huazhong Univ Sci Technol Med Sci 2008; 28(5): 553-557.

24 Gusman H, Santana RB, Zehnder M. Matrix metalloproteinase levels and gelatinolytic activity in clinically healthy and inflamed human dental pulps. Eur J Oral Sci 2002; 110(5): 353-357.

25 Dutta A, Sen T, Banerji A et al. Studies on multifunctional effect of all-trans retinoic acid (ATRA) on matrix metalloproteinase-2 (MMP-2) and its regulatory molecules in human breast cancer cells (MCF-7). J Oncol 2009; 2009: 627840.

26 Clark SD, Kobayashi DK, Welgus HG. Regulation of the expression of tissue inhibitor of metalloproteinases and collagenase by retinoids and glucocorticoids in human fibroblasts. J Clin Invest 1987; 80(5): 1280-1288.

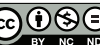

This work is licensed under a Creative Commons AttributionNonCommercial-NoDerivs 3.0 Unported License. The images or other third party material in this article are included in the article's Creative Commons license, unless indicated otherwise in the credit line; if the material is not included under the Creative Commons license, users will need to obtain permission from the license holder to reproduce the material. To view a copy of this license, visit http://creativecommons.org/licenses/ by-nc-nd/3.0/ 